\title{
SCIDiC
}

\author{
International Journal of Dentistry and Oral Science (IJDOS) \\ ISSN: 2377-8075
}

\section{A Novel Technique For Surgical Management Of A Rare Case Of Keloid}

Dr.Rezin Ahmed ${ }^{1}$, Dr.Pradeep D ${ }^{2 *}$, Dr.M.R.Muthusekhar ${ }^{3}$

${ }^{1}$ Saveetha Dental College \& Hospitals, Saveetha Institute of Medical and Technical Sciences, Saveetha University,Chennai 600077,Tamilnadu, India.

${ }^{2}$ Associate professor, Department of oral and maxillofacial surgery, Saveetha Dental college \& Hospitals, Saveetha Institute of Medical and Technical Sciences, Saveetha University, Chennai 600077, Tamilnadu, India.

${ }^{3}$ Professor and Head, Department of oral and maxillofacial surgery, Saveetha Dental college \& Hospitals, Saveetha Institute of Medical and Technical Sciences, Saveetha University, Chennai 600077, Tamilnadu, India.

\section{Introduction}

Z-plasty is a very common interposition surgical technique utilized in plastic and reconstructive surgery to revise scars. Previously referred to as "converging triangular flaps," Z-plasty involves 2 equal and opposing transposition flaps that are raised and transposed along shared access. A benefit of this procedure over other scar revision techniques is it does not require skin excision for the procedure. The technique is used to change the direction of the scar, so it is more easily hidden within a border of facial regions or relaxed skin tension lines (RSTL). The most frequent variants of the basic Z-plasty are planimetric Z-plasty, doubleopposing Z-plasty, compound Z-plasty, unequal triangle Z-plasty, and four-flap Z-plasty. Unequal triangles, also known as the "halfZ," can be subtly altered into an S-plasty to create flap tips that are less susceptible to vascular compromise. S-plasty is useful in areas with an altered dermis, frequently encountered in burns and skin grafts.(Arima et al., 2019; Ogawa, 2019)(Thomas Indresano, 2006). Z-plasty is a very useful plastic surgery technique for closure of wounds without tension. It is usually performed by plastic and cosmetic surgeons. The plastic surgery nurse is usually involved in the monitoring of these patients to ensure that healing is taking place. When closed without tension, Z-plasty has both functional and aesthetic benefit. With a rich case bank established over 3 decades we have been able to publish extensively in our domain (Abdul Wahab et al., 2017; Eapen, Baig and Avinash, 2017; Patil et al., 2017; Jain and Nazar, 2018; J et al., 2018; Marimuthu et al., 2018; Wahab et al., 2018; Abhinav et al., 2019; Ramadorai, Ravi and Narayanan, 2019; Senthil Kumar et al., 2019; Sweta, Abhinav and Ramesh, 2019).

\section{Case Report}

A 26 year old male patient reported to the department of Oral and Maxillofacial surgery with the complaint of facial scar that persisted following a road traffic accident 6 months back.On examination multiple Keloids were noted over the chin region .A scar was running from the lower lip towards the chin and neck on the left side of the face.A scar revision was planned for the 2 most prominent scars as those were the scars which the patient was more concerned with.Patient was prepared for the surgery . Under general anesthesia standard surgical scrubbing and draping was done.Markings for the scar was done (figure). As the scar was long scar multiple $\mathrm{Z}$ plasty had to be done.Multiple equal and opposing transposition flaps were raised and transposed along shared access.Flpas were sutured with 6-0 proline .

\section{Discussion}

The history of the Z-plasty dates back to the early 1800s in a publication at the Philadelphia Hospital Department of Surgery noted by Horner that described single transposition flaps. The geometry of what clinicians know as the Z-plasty was not the same as it is today. At the turn of the century, the "Z-plasty method" became more popular. A publication by Berger in 1904 noted equal limbs and equal angles. In 1914, Morestin proposed multiple Z-plasties. However, it was Limberg, in 1929, who delved into the dynamics of the flap being a rotational and advancement flap. In 1973, Borges provided a review of the developmental history of the Z-plasty.(Kordahi et al., 2018)(Varadharajan, Choudhury and Saleh, 2019).

The indication for a Z-plasty is the lengthening of a contracted linear scar through a flexor crease and changing the direction of a scar to improve cosmetic appearance.(Zhang et al., 2019)(Ahmed and Loh, 2018).

- Treatment of scars that distort facial landmarks.

*Corresponding Author

Dr.Pradeep D,

Associate professor, Department of oral and maxillofacial surgery, Saveetha Dental college \& Hospitals, Saveetha Institute of Medical and Technical Sciences, Saveetha University, Chennai 600077, Tamilnadu, India.

Tel : +919789936383

E-mail: pradeep@saveetha.com

Received: May 31, 2021

Accepted: July 06, 2021

Published: July 19, 2021

Citation: Rezin Ahmed, Pradeep D, M.R.Muthusekhar. A Novel Technique For Surgical Management Of A Rare Case Of Keloid. Int J Dentistry Oral Sci. 2021;8(7):3378-3380. doi: http://dx.doi.org/10.19070/2377-8075-21000687

Copyright: Dr. Pradeep D 2021 . This is an open-access article distributed under the terms of the Creative Commons Attribution License, which permits unrestricted use, distribution and reproduction in any medium, provided the original author and source are credited. 
Image a,b,c,d,e,f,g,h:

(a)\&(b) shows the preoperative images the scars can be appreciated in the image well.(c)Markings for the $Z$ plasty.(d)(e)(f) Intraoperative images multiple $\mathrm{Z}$ plasty is done.(g)Closure with 6-0 poline(h) Image shows the 7 th post operative day

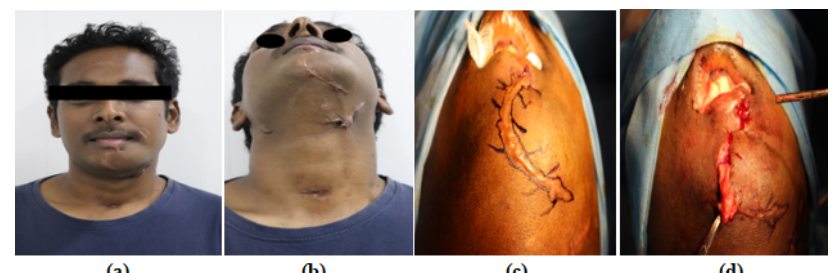

(a)

(b)

(c)

(d)

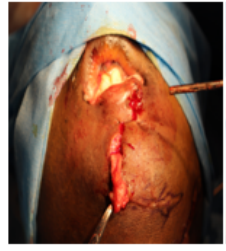

(e)

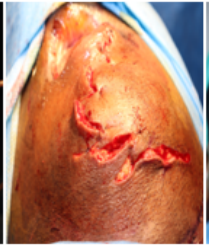

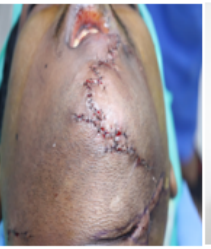

(g)

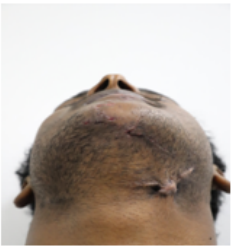

(h)
- Contracted/webbed scars.

- McGregor Flap (to close the secondary defect in the preauricular area in order to decrease the risk of ectropion).

There are no absolute contraindications to the Z-plasty technique. Relative contraindications to Z-plasty include patients with keloids and hypertrophic scars. Other relative contraindications include any factor that may adversely affect wound healing such as poor vascular supply, diseases causing poor vascular supply, uncontrolled diabetes, prior radiation of the tissue, the presence of an active infection, and an uncooperative patient.

A discussion must take place with the patient prior to the start of the procedure. During this discussion, risks and benefits of the procedure should be discussed at length. Postoperative care and follow-up should also be discussed. This is an opportunity for the patient to ask questions to assure understanding. Informed consent must be obtained before starting the procedure. The surgical site is prepped utilizing a sterile antibacterial solution, usually povidone-iodine. Sterile drapes are applied to the area.

\section{Technique}

On a scar that is perpendicular to the lines of least skin tension, a thickened scar may develop due to tension. In an attempt to change the direction of the scar, a basic Z-plasty technique is employed utilizing 60-degree angles. A Z-plasty consists of a central limb. The central limb contains the scar that is to be lengthened or realigned. Each limb is the same length and results in each segment of the $\mathrm{Z}$ contract in different directions. A 60-degree angle will result in $75 \%$ increase in length and a 90 -degree reorientation of tension. Angles of the Z-plasty result in different changes in length and tension orientation. In general, the greater the angle, the greater gain in wound length. A smaller angle has a risk of flap tip necrosis. A broader angle can result in more difficult flap rotation.

In designing the Z-plasty, one must consider the angle of the design. The greater these angles are, the more lengthening will occur; however, the flaps become harder to transpose over one another.
Angles compared to gain in length are as follows

- 30-degree angle results in 25\% gain in length.

- 45-degree angle results in 50\% gain in length.

- 60-degree angle results in 75\% gain in length.

- 75-degree angle results in 100\% gain in length.

- 90 -degree angle results in 125\% gain in length.

After the area has been prepared with sterile solution, the "2 arms" of the z-plasty are drawn at both ends of the scar. It is important to design the Z-plasty prior to injection of the local anesthetic as this will distort the tissue. These should be drawn with angles at 60 degrees to the linear scar, resembling the letter $Z$. The arms should be equal in length with the same angle measure. Next, the area should be anesthetized with a $1 \%$ lidocaine in a 1:100,000 units of epinephrine. Using a No. 15 scalpel, incisions are made into the skin through the marked areas. The area is then undermined at the subcutaneous fat level. Two equallysized flaps should be created and undermined at the level of the subcutaneous fat to create full-thickness flaps. After which, the 2 equal flaps are transposed around each other. This results in a directional change of the original scar. The flaps are then held in place with anchoring sutures. The skin is then closed using interrupted sutures. Topical antibiotics or a nonantibacterial ointment is applied with pressure.

Before performing Z-plasty, the skin should be examined for laxity, and some type of planning must be made as to where the incision will be performed. The main disadvantage of Z-plasty is an increased scar length. In addition, the procedure requires 2 additional incisions. Sometimes, the edge of the incision may become depressed or even necrotic when the angle of rotation is acute.

Z-plasty is a very common interposition surgical technique utilized in plastic and reconstructive surgery to revise scars. The technique can also be used to prevent contracture of linear scars, decrease scar length, reposition malpositioned tissues, closing cutaneous defects, and correcting stenosis. Z-plasty is a technique, which is useful when there is scar crossing relaxing skin tension lines. While a single Z-plasty may be utilized for a scar, a serial/ compound Z-plasty may be used to address larger scars. Understanding the technique of a basic Z-plasty allows the surgeon to 
realize the potential and versatility.

\section{References}

[1]. Abdul Wahab PU, Senthil Nathan P, Madhulaxmi M, Muthusekhar MR, Loong SC, Abhinav RP. Risk Factors for Post-operative Infection Following Single Piece Osteotomy. J Maxillofac Oral Surg. 2017 Sep;16(3):328-332. Pubmed PMID: 28717291.

[2]. Abhinav RP, Selvarasu K, Maheswari GU, Taltia AA. The Patterns and Etiology of Maxillofacial Trauma in South India. Ann Maxillofac Surg. 2019 Jan-Jun;9(1):114-117. Pubmed PMID: 31293938.

[3]. Ahmed M, Loh CYY. Double Z plasty advancement flaps for closure of large defects on the forearm. Int Wound J. 2018 Dec;15(6):1052. Pubmed PMID: 29978940.

[4]. Arima J, Dohi T, Kuribayashi S, Akaishi S, Ogawa R. Z-plasty and Postoperative Radiotherapy for Anterior Chest Wall Keloids: An Analysis of 141 Patients. Plast Reconstr Surg Glob Open. 2019 Mar 13;7(3):e2177. Pubmed PMID: 31044131.

[5]. Eapen BV, Baig MF, Avinash S. An Assessment of the Incidence of Prolonged Postoperative Bleeding After Dental Extraction Among Patients on Uninterrupted Low Dose Aspirin Therapy and to Evaluate the Need to Stop Such Medication Prior to Dental Extractions. J Maxillofac Oral Surg. 2017 Mar;16(1):48-52. Pubmed PMID: 28286384.

[6]. Jain M, Nazar N. Comparative Evaluation of the Efficacy of Intraligamentary and Supraperiosteal Injections in the Extraction of Maxillary Teeth: A Randomized Controlled Clinical Trial. J Contemp Dent Pract. 2018 Sep 1;19(9):1117-1121. Pubmed PMID: 30287714.

[7]. J PC, Marimuthu T, C K, Devadoss P, Kumar SM. Prevalence and measurement of anterior loop of the mandibular canal using CBCT: A cross sectional study. Clin Implant Dent Relat Res. 2018 Aug;20(4):531-534. Pubmed PMID: 29624863.

[8]. Kordahi AM, Karian LS, Theratil PJ, Granick MS. Reconstruction of Simple
Incomplete Syndactyly of the Foot. Eplasty. 2018 Dec 3;18:ic24. Pubmed PMID: 30655932.

[9]. Marimuthu M, Andiappan M, Wahab A, Muthusekhar MR, Balakrishnan A, Shanmugam S. Canonical Wnt pathway gene expression and their clinical correlation in oral squamous cell carcinoma. Indian J Dent Res. 2018 MayJun;29(3):291-297. Pubmed PMID: 29900911.

[10]. Ogawa R. Surgery for scar revision and reduction: from primary closure to flap surgery. Burns Trauma. 2019 Mar 1;7:7. Pubmed PMID: 30891462

[11]. Patil SB, Durairaj D, Suresh Kumar G, Karthikeyan D, Pradeep D. Comparison of Extended Nasolabial Flap Versus Buccal Fat Pad Graft in the Surgical Management of Oral Submucous Fibrosis: A Prospective Pilot Study. J Maxillofac Oral Surg. 2017 Sep;16(3):312-321. Pubmed PMID: 28717289.

[12]. Ramadorai A, Ravi P, Narayanan V. Rhinocerebral Mucormycosis: A Prospective Analysis of an Effective Treatment Protocol. Ann Maxillofac Surg. 2019 Jan-Jun;9(1):192-196. Pubmed PMID: 31293952.

[13]. Senthil Kumar MS, Ramani P, Rajendran V, Lakshminarayanan P. Inflammatory pseudotumour of the maxillary sinus: Clinicopathological report. Oral Surgery. 2019 Aug;12(3):255-9.

[14]. Sweta VR, Abhinav RP, Ramesh A. Role of Virtual Reality in Pain Perception of Patients Following the Administration of Local Anesthesia. Ann Maxillofac Surg. 2019 Jan-Jun;9(1):110-113. Pubmed PMID: 31293937.

[15]. Thomas Indresano, A. Modern Surgical Management of the Temporomandibular Joint. Saunders 2006

[16]. Varadharajan K, Choudhury N, Saleh HA. Modified Z-plasty of the internal nasal valve-To treat mechanical nasal obstruction: How we do it. Clin Otolaryngol. 2019 Nov;44(6):1203-1204. Pubmed PMID: 30710423.

[17]. Wahab PUA, Madhulaxmi M, Senthilnathan P, Muthusekhar MR, Vohra Y, Abhinav RP. Scalpel Versus Diathermy in Wound Healing After Mucosal Incisions: A Split-Mouth Study. J Oral Maxillofac Surg. 2018 Jun;76(6):11601164. Pubmed PMID: 29406253.

[18]. Zhang G, Ju J, Li L, Tang L, Fu Y, Hou R. Combination free foot flaps for digit reconstruction: A retrospective analysis of 37 cases. J Plast Reconstr Aesthet Surg. 2019 May;72(5):729-736. Pubmed PMID: 30595416. 